\title{
Prevalence and Risk Factors for Microalbuminuria in Children with Sickle Cell Disease in the King Abdulaziz University Hospital: A Retrospective Cross-sectional Study
}

\author{
Yahya A Alzahrani ( $\square$ YahyaDahwan@gmail.com ) \\ https://orcid.org/0000-0001-5268-9709 \\ Malak Ali Algarni \\ King Abdulaziz University Hospital \\ Maryam Mohammed Alnashri \\ King Abdulaziz University Hospital \\ Hanan Mohammad AlSayyad \\ King Abdulaziz University Hospital \\ Khadijah Mohammed Aljahdali \\ King Abdulaziz University Hospital \\ Joud Emad Alead \\ King Abdulaziz University Hospital \\ Yara Ali Alhjrsy \\ King Abdulaziz University Hospital \\ Fatma Salih Alzahrani \\ King Abdulaziz University Hospital \\ Osama Safder \\ King Abdulaziz University Hospital
}

Research note

Keywords: Sickle cell disease, microalbuminuria, retrospective study

Posted Date: September 13th, 2019

DOI: https://doi.org/10.21203/rs.2.14382/v1

License: (a) (i) This work is licensed under a Creative Commons Attribution 4.0 International License. Read Full License 
Version of Record: A version of this preprint was published at Cureus on January 12th, 2020. See the published version at https://doi.org/10.7759/cureus.6638. 


\section{Abstract}

Objectives Studies have not addressed microalbuminuria in the sickle cell disease (SCD) pediatric population in Jeddah, Saudi Arabia. This study aimed to determine the prevalence of microalbuminuria and to identify associated risk factors in children with SCD in the King Abdulaziz University Hospital.

Results Overall, $42.5 \%$ of the patients enrolled were Saudi Arabian and $51 \%$ were boys. Patients' mean age was 12.4 years, and the highest percentage (40\%) was in the age group of 15-18 years. The prevalence of microalbuminuria was $9.6 \%$, and hematuria was present in $8 \%$ of cases. The percentage of patients with hematuria in the microalbuminuria group $(22.6 \%)$ was significantly higher than that in the nonmicroalbuminuria group (6.5\%) (P=.007). The percentage of patients with acute chest syndrome was higher in the microalbuminuria group $(26 \%)$ than in the non-microalbuminuria group $(8 \%)(P=0.005)$. The percentage of patients with gallbladder stones was higher in the microalbuminuria group (13\%) than in the non-microalbuminuria group $(2.4 \%)(P=.014)$. The mean number of blood transfusions was higher in the non-microalbuminuria group than in the microalbuminuria group $(P=.002)$. Sickle cell nephropathy manifests as microalbuminuria, begins in the early ages of life, occurs in all types of SCD, and is associated with disease severity.

\section{Introduction}

Sickle cell disease (SCD) is one of the most important autosomal recessive diseases. The prevalence in the Kingdom of Saudi Arabia (KSA) for the sickle-cell trait ranges from 2 to $27 \%$, and up to $2.6 \%$ of individuals develop SCD in KSA. ${ }^{1}$ SCD is characterized by vaso-occlusive events, hemolytic crises, and organ damage. $^{2}$

A chronic complication of SCD is renal impairment, which is a major factor in mortality. ${ }^{3,4}$ This association with mortality is stronger than that observed with an episode of acute stroke, a febrile episode with positive blood culture, acute chest syndrome, and severe acute anemia. ${ }^{5}$ Chronic renal complications occur in 5$18 \%$ of SCD cases, and $>9 \%$ of deaths in young adults are due to renal involvement. ${ }^{4-6}$

In SCD, microalbuminuria is one of the most common clinical manifestations of sickle cell nephropathy $(\mathrm{SCN}),{ }^{7,8}$ which appears to be associated with a more rapid deterioration in renal function. ${ }^{9}$

Microalbuminuria screening in patients with SCD is a predictor of end-organ disease including renal damage. ${ }^{10,11}$

Children with SCD experience hyperfiltration and hyperperfusion, which are associated with renal damage. ${ }^{12,13}$ Early detection of microalbuminuria may represent an important early sign of renal disease. ${ }^{14} \mathrm{~A}$ prolonged period of microalbuminuria precedes persistent proteinuria, which is followed by renal failure in SCD patients. ${ }^{15}$ Varied incidence of microalbuminuria in children with SCD ranges from $18.4 \%$ to $46 \% .{ }^{16-18}$ 
The identification of risk factors for microalbuminuria may allow earlier intervention to prevent renal complications. ${ }^{16}$ Considering the high burden of SCD in the KSA with a prevalence rate of $2.6 \%$ in newborns ${ }^{1}$ in a population of $>24$ million, children with SCD are prone to developing microalbuminuria and chronic renal failure with advancing age.

Research in Saudi Arabia has not addressed this problem. Thus, this study aimed to determine the prevalence of microalbuminuria in children with $S C D$ and to identify risk factors associated with microalbuminuria in children with SCD in the King Abdulaziz University Hospital (KAUH).

\section{Main Text}

\section{Patients and Methods}

The study was approved by the Institutional Review Board of the KAUH. This cross-sectional prevalence study retrospectively reviewed all medical records of children aged 2-18 years diagnosed with SCD in the KAUH Pediatric Sickle Cell Clinic between June 2010 and April 2019. We excluded all patients without urine analysis testing.

Data obtained from the recent outpatient follow-up visit included: sex, age, nationality, weight, height, $A B O$ blood group system, sickle cell genotype, the number of hospitalizations, blood transfusion (BT) status, and the number of transfusions ( $\mathrm{NOH})$. The frequency of the vaso-occlusive events and SCD complications were collected.

Hydroxyurea $(\mathrm{HU})$ therapy and its associations with the number of BTs and $\mathrm{NOH}$ were studied. In urine analysis, microalbuminuria was defined as $>1+$ protein, and red blood cells (RBCs) were counted and defined as hematuria if $>5$.

\section{Statistical analysis}

Descriptive statistics are used to describe study participants' demographic characteristics. Mean \pm standard deviations and median values are used to describe continuous variables. Frequencies with proportions are used to report categorical variables. A comparison of numerical variables between the groups was performed using the independent $t$ test, whereas a comparison of categorical variables was performed using the chi-square and Fisher's exact tests. Statistical significance was set at $P<.05$. All statistical analyses were performed using IBM SPSS statistics, version 23 (IBM, Armonk, NY, USA).

\section{Results}

In total, 322 pediatric patients with SCD were studied for the prevalence of microalbuminuria and its associated factors. Patient characteristics are presented in Table 1. The NOH and BT were not statistically significantly different between patients who did and did not receive HU (Table 2). 
Characteristics of the non-microalbuminuria group (291 patients) and microalbuminuria group (31 patients) and a comparison of different variables between non-microalbuminuria and microalbuminuria patients are shown in Table 3. Only hematuria was statistically significantly different; it was higher in the microalbuminuria group than in the non-microalbuminuria group $(P=0.007)$. There was some difference in the distribution of blood groups $(P=.022)$. The percentage of acute chest syndrome was significantly higher in the microalbuminuria group than in the non-microalbuminuria group $(P=.005)$. The percentage of gallbladder stones was significantly higher in the microalbuminuria group than in the nonmicroalbuminuria group $(P=.014)$. The mean number of BTs was higher in the non-microalbuminuria group than in the microalbuminuria group $(P=0.002)$. The remaining variables showed no significant differences between the groups.

\section{Discussion}

Renal failure secondary to SCD can affect $5--20 \%$ of the adult population. The progressive process starts from childhood and eventually leads to renal failure. ${ }^{19}$ Microalbuminuria is one of the earliest manifestations of SCN. Hence, many studies have been concerned with determining the prevalence of microalbuminuriaamong SCD patients to assess the severity of the condition. ${ }^{20,21}$ We determined the prevalence of microalbuminuria to be $9.6 \%$ among pediatric patients with a mean age of 12.4 years, starting from a very young age (2 years) and continuously progressing to its highest percentage in the young adult group (15-18 years), reaching a prevalence of $51.6 \%$ in this group. Patients' mean age and the average percentage of microalbuminuria among older patients were consistent with a prevalence of $46 \%$ reported by Dharnidharka et $\mathrm{al}^{20}$ and a prevalence of $39-43 \%$ in adults with SCD reported by McBurney et al. ${ }^{16}$ However, the overall prevalence of microalbuminuriaamong all patients $(9.6 \%)$ was lower than the average prevalence reported by those previous studies. Additionally, Alkhunaizi et $\mathrm{al}^{22}$ determined that the prevalence of microalbuminuria among adult Saudi Arabian patients ( $>18$ years) was $25 \%$, which was very similar to our findings with respect to the same age group.

Dharnidharka et $\mathrm{al}^{20}$ and McBurney et $\mathrm{al}^{16}$ reported that no microalbuminuria was detected in children $<7$ years old. Conversely, we found that $9.7 \%$ of microalbuminuria patients were aged $2-5$ years. These findings were supported by Aloni et $\mathrm{al}^{23}$ who confirmed the presence of microalbuminuria among their patients aged $<7$ years. This early deterioration of glomerular function could be explained by the presence of certain factors including a genetic predisposition, the level of fetal hemoglobin ( $\mathrm{HbF}$ ), environmental factors, efficacy of medical care, and lifestyle in the developing countries. ${ }^{24}$ Another reasonable explanation for these contradictory results is our study's small sample size. However, 104 and 151 patients were enrolled in the studies by Dharnidharka et al ${ }^{20}$ and by McBurney et al, ${ }^{16}$ respectively.

Interestingly, when compared the microalbuminuria and non- microalbuminuria groups, there was no statistical difference in terms of age $(P=.432)$, which indicated that age was not a defining variable for both groups. However, age was a defining variable in the progression of microalbuminuria in the affected group. 
A female predominance of microalbuminuria has been reported in the literature. Jones et al reported a prevalence of $9.7 \%$ of microalbuminuria among female patients and $6.1 \%$ among male patients. ${ }^{8}$ Further, Okpere ET al ${ }^{25}$ reported consistent results of female predominance (45.3\%) compared to male predominance $(20.4 \%)$. However, no significant difference in sex was detected between the microalbuminuria and non-microalbuminuria groups in our study or the studies of McBurney et $\mathrm{al}^{16}$ and Dharnidharka et al. ${ }^{20}$ Consequently, additional study is necessary to provide further evidence regarding these contrary results.

Our findings demonstrated that microalbuminuria occurs in most of the hemoglobin genotypes, with the highest percentage in the $\mathrm{Hb}$-ss genotype $(74.2 \%)$ in the microalbuminuriagroup, which is similar to that reported in previous studies conducted by Wigfall et al. ${ }^{26}$ However, no microalbuminuriawas detected in the HB-S $\beta 0$ (Beta-Zero) thalassemia sub-group. In most previous studies, patients with S $\beta$-thalassemia were few in number, and there have been limited studies with mixed results about this patient group. Becton et $\mathrm{al}^{21}$ reported that only one patient with $\mathrm{S} \beta$-thalassemia had microalbuminuria.

We further examined the percentage of several clinical complications that may be associated with microalbuminuria (Table 3). Next, we compared the microalbuminuriaand non-microalbuminuria groups to identify definitive variables that significantly varied between the groups. Interestingly, we found that most patients in the microalbuminuriagroup experienced acute chest syndromes, gallbladder stones, osteomyelitis, pneumonia, and spleen sequestration, but none reported priapism, avascular necrosis, aplasia, stroke, acute coronary syndrome (ACS), or dactylitis. These findings were consistent with those reported by Dharnidharka et $\mathrm{al}^{20}$ and McBurney et al, ${ }^{16}$ who found no significant correlation between microalbuminuriaand stroke. McBurney et $\mathrm{al}^{16}$ and Kalpathi et al ${ }^{21}$ reported no significant correlation between microalbuminuriaand ACS. We found a significant association between acute chest syndrome and the microalbuminuria group $(P=.005)$, which was consistent with other findings reported by Alvarez et al. $^{27}$

In contrast Bodas et $\mathrm{al}^{28}$ reported that the glomerular filtration rate was not correlated to episodes of stroke or acute chest syndrome, which suggests that the etiologies of these complications may differ from the etiologies of the development of SCN. However, only 48 patients were enrolled in their study and the small sample size, compared to our sample, may have likely influenced the significant correlation between the two conditions.

Furthermore, we found a significant correlation between the microalbuminuriagroup and development of gallbladder stones ( $P=.014 \%$ ). Our findings were consistent with those of Alexander-Reindorf et $\mathrm{al}^{29}$ and Bond et al, ${ }^{30}$ who reported a significantly higher morbidity and more hospital admissions for SCD patients with gallbladder stones. Additionally, the mean age of the microalbuminuriagroup was 13.74 years, which was consistent with Martins et al's ${ }^{31} 11$ - and 29-year-old study cohort with a higher prevalence of cholelithiasis and gallbladder stones. 
$\mathrm{HU}$ is an effective drug associated with an increasing hemoglobin concentration, $\mathrm{MCV}$, and $\mathrm{HbF}$ level in adults and children. High levels of $\mathrm{HbF}$ reduces sickling of RBCs and glomerular damage of the kidney. ${ }^{32}$

We attempted to identify a correlation between the administration of $\mathrm{HU}$ and the NOH or BTs in SCD patients. However, we found no significant effect of administrating the drug and $\mathrm{NOH}$ or $\mathrm{BT}$ in both groups $(P=.7)$. This finding could suggest that the effect of $\mathrm{HU}$ as a renoprotective agent is effective when treatment starts during infancy. ${ }^{27}$

We found that the number of BTs was significantly associated with a decreased level of microalbuminuria. This finding suggests that BTs are a renoprotective process in the management of SCD. Alvarez et al. ${ }^{27}$ reported similar results when they indicated that starting transfusion at an early age could help the kidney and hinders the deterioration of SCN. However, the side effects of transfusion, iron overload, must be considered before starting the process. Aloni et $\mathrm{al}^{23}$ reported that $\mathrm{BT}$ is not a significant factor when comparing bothgroups.

Kalpathi et al ${ }^{21}$ stated that $36 \%$ of SCD patients presented with hematuria. However, they reported no significant difference in the level of hematuria between the microalbuminuriaand non- microalbuminuria groups. We determined the percentage of hematuria among SCD patients and found a statistically significant difference in the percentage of hematuria between the two groups $(P=.007)$. These results were consistent with the findings of Sesso et al, ${ }^{34}$ who reported a higher level of hematuria among $\mathrm{Hb}$-ss and $\mathrm{Hb}$-as groups. They stated that hematuria is caused by increased sickling of RBCs in the renal medulla, resulting in extravasation and ischemia.

We also determined that most SCD patients have $\mathrm{ORh}+$ blood, which was significantly different between the two groups $(P=.022)$. This result is consistent with that of Alagwu et al, ${ }^{35}$ who reported a percentage of $63 \%$ for blood group 0 among $\mathrm{Hb}$-ss patients. This finding could be explained by the fact that blood group $\mathrm{O} \mathrm{Rh}+$ is the most prevalent group among all humans.

In conclusion, our findings highlight the importance of early investigations, e.g., urine analysis for assessment of microalbuminuria and hematuria, and determination of the degree SCN. The fact that average mean BT was significantly higher in the non-microalbuminuria group than in the microalbuminuria group could suggest a protective role of transfusion in the development of microalbuminuria. However, further investigations need to be conducted to confirm our results. Besides, we reported significantly higher rates of acute chest syndrome and gallbladder stones in microalbuminuria patients, which must be considered, and special care needs to be provided to them. We recommend routine screening of microalbuminuria and hematuria for SCD patients.

\section{Limitations}

Patients visiting the pediatric hematology clinic with a diagnosis of SCD do not routinely undergo urine analysis tests, and data were collected solely from registration records. 


\section{List Of Abbreviations}

SCD, sickle cell disease; KSA, Kingdom of Saudi Arabia; KAUH, King Abdulaziz University Hospital; ACS, acute coronary syndrome; $\mathrm{HU}$, hydroxyurea; $\mathrm{RBC}$, red blood cell; $\mathrm{MCV}$, mean corpuscular volume; $\mathrm{HbF}$, fetal hemoglobin; $\mathrm{BT}$, blood transfusion; $\mathrm{SCN}$, sickle cell nephropathy; $\mathrm{NOH}$, number of transfusions

\section{Declarations}

\section{Ethics approval and consent to participate}

The study was approved by the Institutional Review Board of the King Abdul-Aziz University Hospitalreference number: 186-19).

\section{Consent for publication}

Not applicable.

\section{Availability of data and materials}

The datasets used and analyzed during the current study are available from the corresponding author on reasonable request.

\section{Competing interests}

The authors declare that they have no competing interests

\section{Funding}

Not applicable.

\section{Authors' contributions}

Yahya $A A$, the first author, contributed to the conception and design of the study, analysis and interpretation of data, and final approval of the version of the manuscript to be published.

Yara $A A$ made substantial contribution to the acquisition of data and drafting of the article.

OYS contributed to the conception and design of the study, and critical revision of the article for important intellectual content.

MAA made substantial contribution to the acquisition of data and drafting of the article. 
MMA made substantial contribution to the conception and design of the study, and drafting of the article.

HMA made substantial contribution to the acquisition of data and drafting of the article.

JEA made substantial contribution to the acquisition of data and critical revision of the article for important intellectual content.

KMA made substantial contribution to the conception and design of the study, and drafting of the article.

FSA contributed to the conception and design of the study, critical revision of the article for important intellectual content, and final approval of the version of the manuscript to be published.

\section{Acknowledgements}

Not applicable.

\section{References}

1. Jastaniah W. Epidemiology of sickle cell disease in Saudi Arabia. Ann Saudi Med. 2011;31:289-93.

2. Quinn CT. Sickle cell disease in childhood: from newborn screening through transition to adult medical care. Pediatr Clin. 2013;60:1363-81.

3. Powars DR, Chan LS, Hiti A, Ramicone E, Johnson C. Outcome of sickle cell anemia: a 4-decade observational study of 1056 patients. Medicine (Baltimore). 2005;84:363-76.

4. Powars DR, Elliott-Mills DD, Chan L, Niland J, Hiti AL, Opas LM, et al. Chronic renal failure in sickle cell disease: risk factors, clinical course, and mortality. Ann Intern Med. 1991;115:614-20.

5. Platt OS, Brambilla DJ, Rosse WF, Milner PF, Castro O, Steinberg MH, et al. Mortality in sickle cell disease-life expectancy and risk factors for early death. N Engl J Med. 1994;330:1639-44.

6. Guasch A, Navarrete J, Nass K, Zayas CF. Glomerular involvement in adults with sickle cell hemoglobinopathies: prevalence and clinical correlates of progressive renal failure. J Am Soc Nephrol. 2006;17:2228-35.

7. Embury SH, Hebbel RP, Mohandas N, Steinberg MH. Sickle cell disease: basic principles and clinical practice. New York: Raven Press; 1994.

8. Eke CB, Okafor HU, Ibe BC. Prevalence and correlates of microalbuminuria in children with sickle cell anaemia: Experience in a tertiary health facility in Enugu, Nigeria. Int J Nephrol. 2012;2012:240173.

9. Pham PT, Pham PC, Wilkinson AH, Lew SQ. Renal abnormalities in sickle cell disease. Kidney Int. 2000;57:1-8.

10. Motala AA. Micro-albuminuria in diabetes mellitus-significance and screening. S Afr Med J. 1998;88:365-6.

11. Mogensen CE. Microalbuminuria as a predictor of clinical diabetic nephropathy. Kidney Int. 1987;31:673-89. 
12. Guasch A, Cua M, Mitch WE. Early detection and the course of glomerular injury in patients with sickle cell anemia. Kidney Int. 1996;49:786-91.

13. Etteldorf JN, Tuttle AH, Clayton GW. Renal function studies in pediatrics: I. Renal hemodynamics in children with sickle cell anemia. AMA Am J Dis Child. 1952;83:185-91.

14. Aoki RY, Saad ST. Microalbuminuria in sickle cell disease. Braz J Med Biol Res. 1990;23:1103-6.

15. Foucan L, Bourhis V, Etienne-Julan M, Salmi RL. A randomized trial of captopril for microalbuminuria in normotensive adults with sickle cell anemia. Am J Med. 1998;104:339-42.

16. McBurney PG, Hanevold CD, Hernandez CM, Waller JL, McKie KM. Risk factors for microalbuminuria in children with sickle cell anemia. J Pediatr Hematol Oncol. 2002;24:473-7.

17. King L, MooSang M, Miller M, Reid M. Prevalence and predictors of microalbuminuria in Jamaican children with sickle cell disease. Arch Dis Child. 2011;96:1135-9.

18. Ochigbo SO, Jacob UJ, Nlemadim AC, Kudirat OO. Comparative efficacy of serum ceatinine and microalbuminuria in detecting early renal injury in asphyxiated babies in Calabar, Nigeria. Int J Child Heal Nutr. 2016;5:147-51.

19. McKie KT, Hanevold CD, Hernandez C, Waller JL, Ortiz L, McKie KM. Prevalence, prevention, and treatment of microalbuminuria and proteinuria in children with sickle cell disease. J Pediatr Hematol Oncol. 2007;29:140-4.

20. Dharnidharka VR, Dabbagh S, Atiyeh B, Simpson P, Sarnaik S. Prevalence of microalbuminuria in children with sickle cell disease. Pediatr Nephrol. 1998;12:475-8.

21. Becton LJ, Kalpatthi RV, Rackoff E, Disco D, Orak JK, Jackson SM, et al. Prevalence and clinical correlates of microalbuminuria in children with sickle cell disease. 2010;25:1505-11.

22. Alkhunaizi AM, Al-Khatti AA, Alkhunaizi MA. Prevalence of microalbuminuria in adult patients with sickle cell disease in Eastern Saudi Arabia. Int J Nephrol. 2018;2018:5015764.

23. Aloni MN, Mabidi JL, Ngiyulu M, Ekulu PM, Mbutiwi Fl, Makulo JR, et al. Prevalence and determinants of microalbuminuria in children suffering from sickle cell anemia in steady state. 2017;10:479-86.

24. Hay SI, Gupta S, Weatherall DJ, Williams TN. Global burden of sickle cell anaemia in children under five, 2010-2050: Modelling based on demographics, excess mortality, and interventions. PLoS Med. 2013;10:e1001484.

25. Okpere AN, Anochie IC, Eke FU. Prevalence of microalbuminuria among secondary school children. Afr Health Sci. 2012;12:140-7.

26. Delbert RW, Ware RE, Burchinal MR, Kinney TR, Foreman JW. Prevalence and clinical correlates of glomerulopathy children with sickle cell disease. 2000;136:749-53.

27. Alvarez O, Montane B, Lopez G, Wilkinson J, Miller T. Early blood transfusions protect against microalbuminuria in children with sickle cell disease. 2006;47:71-6.

28. Bodas P, Huang A, Riordan MAO, Sedor JR, Dell KM. The prevalence of hypertension and abnormal kidney function in children with sickle cell disease-a cross sectional review. BMC Nephrol. 2013;14:237. 
29. Alexander-Reindorf C, Nwaneri RU, Worrell RG, Ogbonna A, Uzoma C. The significance of gallstones in children with sickle cell anemia. J Natl Med Assoc. 1990;82:645-50.

30. Bond LR, Hatty SR, Horn MEC, Dick M, Meire HB, Bellingham AJ. Gall stones in sickle cell disease in the United Kingdom. Br Med J (Clin Res Ed). 1987;295:234-6.

31. Martins RA, Soares RS, Vito FB, Barbosa VF, Silva SS, Moraes-Souza H, et al. Cholelithiasis and its complications in sickle cell disease in a university hospital. Rev Bras Hematol Hemoter. 2017;39:2831.

32. Kinney TR, Helms RW, Branski EE, Ohene-Frempong K, Wang W, Daeschner C, et al. Safety of hydroxyurea in children with sickle cell anemia: results of the HUG-KIDS study, a phase I/II trial. Pediatric Hydroxyurea Group. Blood. 1999;94:1550-4.

33. Aygun B, Mortier NA, Smeltzer MP, Shulkin BL, Hankins JS, Ware RE. Hydroxyurea treatment decreases glomerular hyperfiltration in children with sickle cell anemia. Am J Hematol. 2013;88:116-9.

34. Sesso R, Almeida MA, Figueiredo MS, Bordin JO. Renal dysfunction in patients with sickle cell anemia or sickle cell trait. Braz J Med Biol Res. 1998;31:1257-62.

35. Alagwu EA, Akukwu D, Uloneme GC. ABO/Rhesus blood group and correlation with sickle cell disease and type-ii diabetes mellitus in South East and South-South of Nigeria. UK Journal of Pharmaceutical and Biosciences. 2016;4:78-82.

\section{Tables}

Table 1: Descriptive statistics of all patients enrolled in the study $(\mathrm{N}=322)$ 


\begin{tabular}{|c|c|c|}
\hline Variable & $\mathbf{N}$ & Percentage \\
\hline \multicolumn{3}{|l|}{ Nationality } \\
\hline Non-Saudi Arabian & 185 & 57.5 \\
\hline Saudi Arabian & 137 & 42.5 \\
\hline \multicolumn{3}{|l|}{ Sex } \\
\hline Female & 157 & 48.8 \\
\hline Male & 165 & 51.2 \\
\hline \multicolumn{3}{|l|}{ Age group } \\
\hline 2 to 5 years & 30 & 9.3 \\
\hline 6 to 10 years & 87 & 27.0 \\
\hline 11 to 14 years & 77 & 23.9 \\
\hline 15 to 18 years & 128 & 39.8 \\
\hline \multicolumn{3}{|l|}{ Sickle cell genotype } \\
\hline Hemoglobin SB 0 (Beta-zero) thalassemia & 4 & 1.2 \\
\hline Hemoglobin SB+ (beta) thalassemia & 41 & 12.7 \\
\hline Hemoglobin SS disease (sickle cell disease) & 233 & 72.4 \\
\hline Sickle cell trait (hemoglobin S disease) & 44 & 13.7 \\
\hline \multicolumn{3}{|l|}{ Microalbuminuria } \\
\hline No & 291 & 90.4 \\
\hline Yes & 31 & 9.6 \\
\hline \multicolumn{3}{|l|}{ Hematuria } \\
\hline No & 296 & 91.9 \\
\hline Yes & 26 & 8.1 \\
\hline \multicolumn{3}{|l|}{ Blood type } \\
\hline A RhD negative (A-) & 3 & 0.9 \\
\hline A RhD positive $(\mathrm{A}+)$ & 84 & 26.1 \\
\hline AB RhD positive $(A B+)$ & 15 & 4.7 \\
\hline B RhD negative (B-) & 3 & 0.9 \\
\hline B RhD positive $(\mathrm{B}+)$ & 32 & 9.9 \\
\hline O RhD negative (O-) & 9 & 2.8 \\
\hline O RhD positive $(\mathrm{O}+)$ & 176 & 54.7 \\
\hline \multicolumn{3}{|l|}{ Blood transfusions } \\
\hline No & 143 & 44.4 \\
\hline Yes & 179 & 55.6 \\
\hline \multicolumn{3}{|l|}{ Frequency of: } \\
\hline Pneumonia & 30 & 9.3 \\
\hline Priapism & 3 & 0.9 \\
\hline Avascular necrosis & 3 & 0.9 \\
\hline Acute chest syndrome & 31 & 9.6 \\
\hline Aplasia & 2 & 0.6 \\
\hline Stroke & 14 & 4.3 \\
\hline Acute coronary syndrome & 10 & 3.1 \\
\hline Dactylitis & 3 & 0.9 \\
\hline Spleen sequestration & 24 & 7.5 \\
\hline Gallbladder stones & 11 & 3.4 \\
\hline Osteomyelitis & 23 & 7.1 \\
\hline \multicolumn{3}{|l|}{ Hydroxyurea therapy } \\
\hline No & 208 & 64.6 \\
\hline Yes & 114 & 35.4 \\
\hline Reasons for prescribing hydroxyurea & & \\
\hline
\end{tabular}




\begin{tabular}{|c|c|c|c|}
\hline \multicolumn{2}{|l|}{ Pain } & \multicolumn{2}{|c|}{$107 \mid 33.2$} \\
\hline Acute chest syndrome & & 9 & 2.8 \\
\hline Transient ischemic attack & & 0 & 0.0 \\
\hline \multicolumn{4}{|l|}{ Numerical variable } \\
\hline & Mean & SD & Median \\
\hline Age (years) & 12.43 & 4.64 & 13.00 \\
\hline Number of hospitalizations & 16.14 & 35.56 & 5.00 \\
\hline Number of blood transfusions & 8.67 & 26.71 & 1.00 \\
\hline
\end{tabular}

SD, standard deviation

Table 2: Associations of hydroxyurea treatment with the number of hospitalizations and number of transfusions 


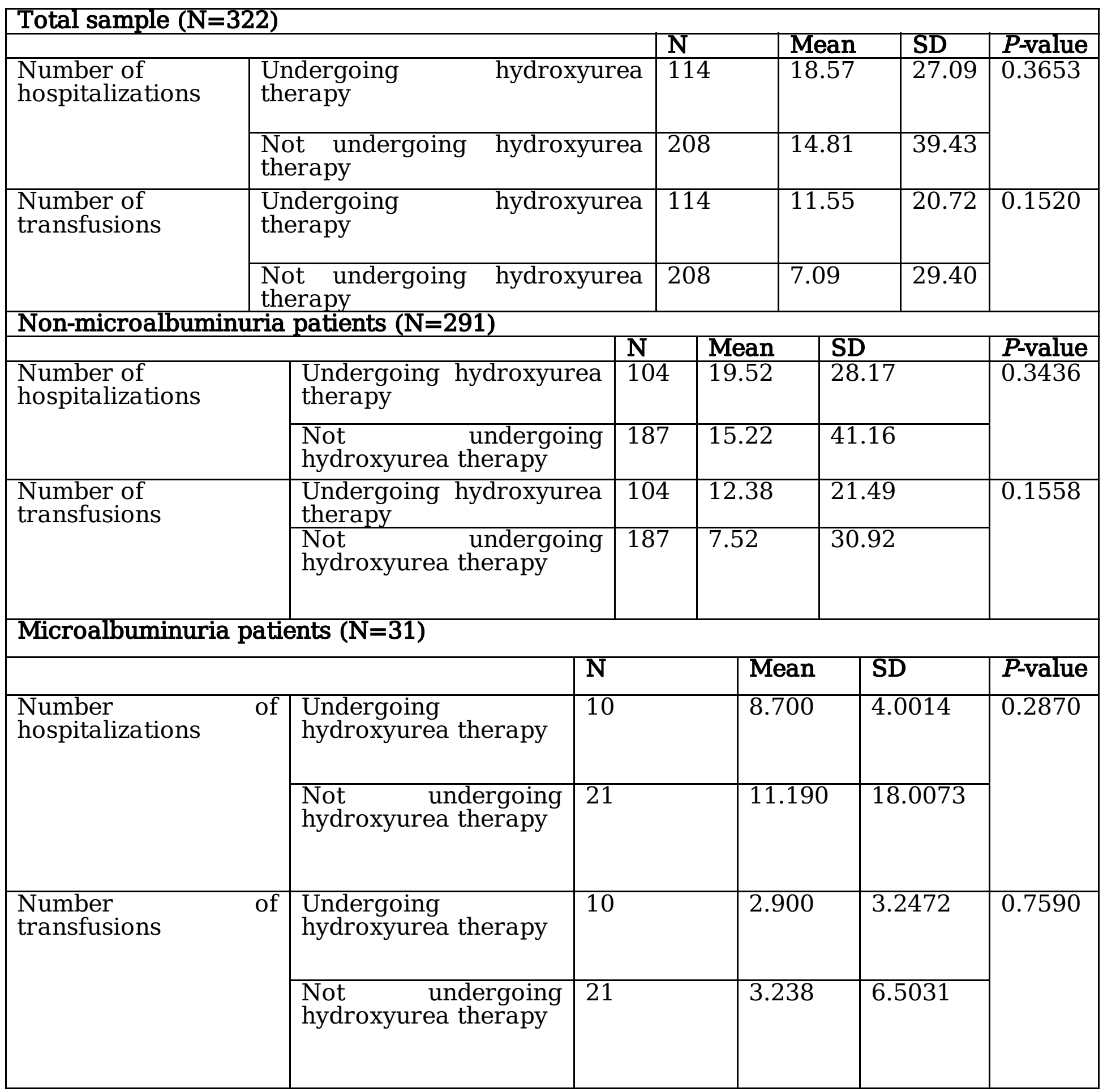

SD, standard deviation

Table 3: Comparison of different variables between non-microalbuminuria and microalbuminuria patients 
Nationality

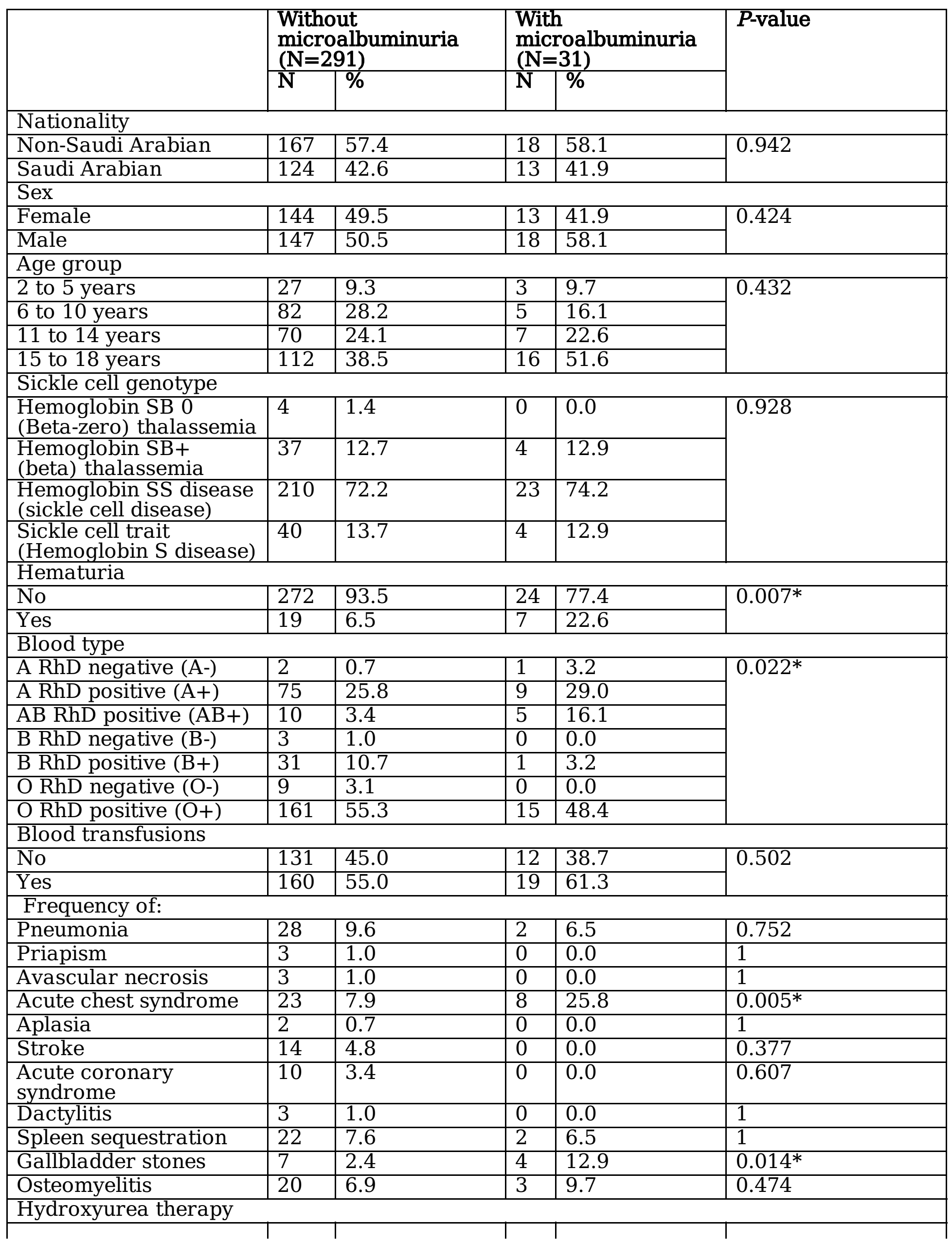




\begin{tabular}{|c|c|c|c|c|c|c|c|}
\hline No & 187 & \multirow{2}{*}{$\begin{array}{l}64.3 \\
35.7\end{array}$} & 21 & 67.7 & \multirow{2}{*}{\multicolumn{3}{|c|}{0.7}} \\
\hline Yes & 104 & & 10 & 32.3 & & & \\
\hline \multicolumn{8}{|c|}{ Reasons of Hydroxyurea therapy } \\
\hline Pain & 98 & 33.7 & 9 & 29.0 & \multicolumn{2}{|c|}{0.602} & \\
\hline Acute chest syndrome & 8 & 2.7 & 1 & 3.2 & & 03 & \\
\hline \multicolumn{8}{|l|}{ Numerical variable } \\
\hline & \multicolumn{3}{|c|}{ Without microalbuminuria } & \multicolumn{3}{|c|}{ With microalbuminuria } & $P$-value \\
\hline & Mear & \begin{tabular}{l|l} 
SD \\
\end{tabular} & Median & Mean & SD & Median & \\
\hline Age & $12.2 \mathrm{~s}$ & 4.62 & 12.00 & 13.74 & 4.68 & 15.00 & 0.098 \\
\hline $\begin{array}{l}\text { Number of } \\
\text { hospitalizations }\end{array}$ & 16.76 & 37.05 & 4.00 & 10.39 & 14.91 & 8.00 & 0.068 \\
\hline Number of transfusions & 9.26 & 27.97 & 1.00 & 3.13 & 5.60 & 1.00 & $0.002^{*}$ \\
\hline
\end{tabular}

SD, standard deviation; *, Significant $P$-value 